\title{
EVALUATION OF ANTIOXIDANT, ANTIBACTERIAL, ANTIHEMOLYTIC, AND PHYOCHEMICAL PROPERTIES OF FICUS BENJAMINA, FICUS INFECTORIA, AND FICUS KRISHNAE
}

\author{
PRABHJOT SINGH JASSAL*, MONIKA SHARMA \\ Department of Biotechnology, School of Bioengineering and Biosciences, Lovely Professional University, Punjab - 1440111, Tamil Nadu, \\ India. Email: prabhjot.jassal@lpu.co.in
}

Received: 19 February 2018, Revised and Accepted: 22 December 2018

\section{ABSTRACT}

Objective: The study was conducted for the evaluation of antioxidant, antibacterial, antihemolytic, and phytochemical activity of Ficus benjamina (FB), Ficus infectoria (FI), and Ficus krishnae (FK).

Methods: The antioxidant analysis of FB, FI, and FK was done by 1-diphenyl-2-picrylhydrazyl (DPPH) radical scavenging and nitric oxide (NO) scavenging assay. Evaluation was performed for antibacterial activity against Clostridium perfringens and Staphylococcus aureus by an agar well diffusion method. Hemolytic assay was performed with red blood cell suspension for evaluating antihemolytic activity. Standard protocols were used for phytochemical activity.

Results: In the results of DPPH antioxidant activity assay, it was found that DPPH inhibition was significantly increased with increasing amount of extract. For NO scavenging assay, ANOVA revealed that the inhibition of NO is not significantly affected with an increase in the amount of extract used. Results of antibacterial activity revealed that methanolic extract of FI shows a maximum zone of inhibition (30.5 mm) against $S$. aureus and aqueous extract of FK shows a maximum zone of inhibition (28 mm) against $C$. perfringens. The antihemolytic activity of FB, FI, and FK was performed by measuring percentage inhibition of plant extracts at different concentrations. FK has shown maximum percentage inhibition activity, i.e., $28.64 \%$ at $60 \mu \mathrm{g} / \mathrm{ml}$, whereas FB shows minimum inhibition activity, i.e. $2.7 \%$ at $40 \mu \mathrm{g} / \mathrm{ml}$. Flavonoid content was found to be $0.593 \mu \mathrm{g} / \mathrm{ml}, 0.783 \mu \mathrm{g} / \mathrm{ml}$, and $1.023 \mu \mathrm{g} / \mathrm{ml}$, whereas phenolic content was found to be $0.267 \mu \mathrm{g} / \mathrm{ml}, 0.298 \mu \mathrm{g} / \mathrm{ml}$, and $0.355 \mu \mathrm{g} / \mathrm{ml}$ for FB, FI, and FK, respectively.

Conclusion: FB, FI, and FK extracts contain various phytochemicals which confirm that these plants can be used for therapeutic use and traditional medicine. The methanolic as well as aqueous extracts of the plants have shown the potential to kill the tested microorganism $(C$. perfringens and $S$. aureus) and hence can be used as an antibiotic and potential antibacterial.

Keywords: Antibacterial, Extracts, Phytochemicals, Antioxidant activity.

(C) 2019 The Authors. Published by Innovare Academic Sciences Pvt Ltd. This is an open access article under the CC BY license (http://creativecommons. org/licenses/by/4. 0/) DOI: http://dx.doi.org/10.22159/ajpcr.2019.v12i3.25351

\section{INTRODUCTION}

Disease and health are two vital factors that go simultaneously. About $75-95 \%$ of world's population still rely on plants in either way for the treatment of diseases or as primary source for health care [1]. Ficus benjamina (FB) (Moraceae) is an evergreen tree which is native to Southeast Asia and commonly known as weeping fig. Various parts of this plant have been broadly used as traditional medicine to treat anti-dysentery and skin disorders [2]. It is among the high demand ornamental plants for landscape purpose and beautification in Nigeria. It exhibits flowering performance during winter months and best considered for pollution tolerant (greenhouse gases) [3]. The common follow of multiplication for these for the most part of the perennial ornamental plants is using vegetative plant parts which include leaves, stem, terminal buds, and also roots due to its simplicity and practicability $[4,5]$. The accomplishment of breeding by stem cutting is exceedingly inadequate due to its low capability for the formation of adventitious root limiting its commercial production by growers and nursery owners who have encountered difficulty and recorded very low survival rate in their propagation [6]. A study of phytochemicals has led to characterization and isolation of the bioactive compounds with discovering some new efficacies [7].

Ficus infectoria (FI) is a large perennial and medicinal tree found throughout Asia and belongs to Moraceae family. It is also called as "peepal tree" or "the sacred fig tree" due to mythological background in spiritual places in India [8]. The stem bark of the tree is used in the production of medicines such as antiseptic medicine or astringent [9].
This plant has proved to be the source of bioactive molecules which have antidiabetic properties. It was for the $1^{\text {st }}$ time when an antidiabetic biomolecule named stigmasterol was isolated from its leaves [10]. Similarly, research work is being carried out for the isolation of other unknown bioactive molecules that are active against different diseases which can be further used in future, as major constituents of drugs. Its bark showed the presence of bergapten, lanosterol, ß-sitosterol, stigmasterol, leucoanthocyanidin, etc. [11,12]. Various amino acids such as alanine, threonine, and tyrosine have also been reported in its seeds. The crude latex of this tree showed the presence of a serine protease which was further named as religiosin, an acidic protein which plays an important role in the cheese production and shows detergent activity [13]

Ficus krishnae (FK) is also called as Krishna's butter cup or Krishna fig in English in India and Sri Lanka [14]. When aqueous extract of this plant was administered with hypercholesterolemic rabbits, lipid peroxidation level was decreased and the free radicals were scavenged like superoxide ions. It occurred due to antioxidants increased availability. Thus, this plant exhibits properties to decrease cholesterol levels [15]. A study on wound healing activity was investigated using povidine-iodine $(5 \%)$ as a standard drug. When $10 \%$ leaf extract of this plant was used on wound, there was a decrease in epithelialization period when it was compared with the control group. It was further reported that collagen content can be increased by tannins, which helps in the prevention of wound healing [16]. 


\section{METHODS}

\section{Plant collection}

Matured plants of FB, FI, and FK were authorized from Forest and Wildlife Department, Paryavaran Bhawan, Chandigarh, and collected from Botanical Garden, Chandigarh.

\section{Chemicals}

Nutrient broth, nutrient agar, nitric acid, methanol, methanol, Wagner's reagent, Keller kelliani's reagent, $\mathrm{NaOH}$, ferric chloride, $\mathrm{HCl}$, 1-diphenyl2-picrylhydrazyl (DPPH), and phosphate-buffered saline (PBS) were used.

\section{Extract preparation}

Aqueous extract

From the fresh leaves and stems of test plant, water was to be drawn out. Delusive plant leaves and stems remain were collected to be abraded methodically in tap water 3-5 times. Standardization of test plant foliage and stems was done with $100 \mathrm{ml}$ of double-distilled water followed by centrifugation at $1000 \mathrm{rpm}$ for $5 \mathrm{~min}$ so that liquid medium can get discrete from debris and other particles. In the falcon tubes, supernatant was collected and kept below ambient temperature [17].

\section{Methanol extract}

About $5 \mathrm{~g}$ crushed dried plant was taken and added to $100 \mathrm{ml}$ of methanol of the quantified forte in a flask for $24 \mathrm{~h}$. It was kept in shaking incubator for $6 \mathrm{~h}$ and kept still for next $18 \mathrm{~h}$. Then, sieve it swiftly and evaporate around $25 \mathrm{ml}$ of filtrate to dryness and dry at $105^{\circ} \mathrm{C}$ [17].

\section{Acetone extract}

About $5 \mathrm{~g}$ crushed dried plant was taken and added to $100 \mathrm{ml}$ of acetone of the quantified forte in a flask for $24 \mathrm{~h}$. It was kept in shaking incubator for $6 \mathrm{~h}$ and kept still for rest $18 \mathrm{~h}$. Then, sieve it swiftly and evaporate around $25 \mathrm{ml}$ of filtrate to dryness and dry at $105^{\circ} \mathrm{C}$ [17]

\section{Preparation of sterile disc}

Whatman No. 1 filter paper was punched into 5-mm disc form, followed by sterilization, and then dipped in extracts. Solvent from the extract should not flow to the outside surface from the discs.

\section{Antioxidant analysis \\ DPPH radical scavenging assay}

Free radical scavenging capacity of different extracts was measured by DPPH assay method. Here, only those extracts were used which were soluble in methanol, and their various concentrations were prepared by dilution method [18]. Freshly prepared DPPH solution was taken in the test tubes, and extracts were added which was followed by serial dilutions $(5-50 \mu \mathrm{g} / \mathrm{ml})$ to each test tube so that the final volume would become $5 \mathrm{ml}$. The absorbance was read at $517 \mathrm{~nm}$ after 30 min using a spectrophotometer. Gallic acid was used as a standard. Control sample was equipped, which was containing the same volume without any extract and standard, and the absorbance was read at $517 \mathrm{~nm}$ using a spectrophotometer [19].

\section{Nitric oxide (NO) scavenging assay}

NO formed during its reaction with oxygen or with superoxide such as $\mathrm{NO}_{2}, \mathrm{~N}_{2} \mathrm{O}_{4}$, and $\mathrm{N}_{3} \mathrm{O}_{4}$ is very reactive. This radical plays an important role in various inflammatory processes. $\mathrm{NO}$ is generated from sodium nitroprusside and is measured by the Griess reagent. Sodium nitroprusside in aqueous solution at physiological $\mathrm{pH}$ spontaneously generates $\mathrm{NO}_{2}$ which interacts with oxygen to produce nitric ions that can be estimated by the use of Griess reagent [20].

The NO radical production at persistent levels results in direct tissue toxicity, whereas chronic expression of NO radical is allied with various inflammatory conditions which include juvenile diabetes, arthritis, multiple sclerosis, and ulcerative colitis [20].

\section{Antibacterial assay}

Agar disc diffusion method was used for the analysis of antimicrobial activity. Two bacterial cultures, i.e., Clostridium perfringens and Staphylococcus aureus were used. Aqueous, methanolic, and acetonic extracts were subjected to screening for antibacterial activity by disc diffusion method. On an agar plate where bacteria were sited, discs containing antibiotics were placed and were left to nurture. When an extract impregnated disk is placed on the agar that was previously inoculated with the test bacterium, the extract starts to diffuse radially outward through the agar by producing a gradient. A clear zone around the disc indicated the antimicrobial effect of the plant extracts. Wider the zone that surrounds a disk, the more susceptible the pathogen is to a particular extract.

\section{Phytochemical analysis}

Parts of medicinal plants were subjected to screening for the presence or absence of both primary and secondary metabolites [21].

\section{Alkaloids (Wagner's reagent)}

About $1 \mathrm{ml}$ plant extract was treated with 4-5 drops of Wagner's reagent and observed for formation of reddish brown precipitate (or coloration). Wagner's reagent was mixed $1.27 \mathrm{~g}$ of iodine and $2 \mathrm{~g}$ potassium iodide in $100 \mathrm{ml}$ of water

\section{Carbohydrates (Molisch's test)}

$2 \mathrm{ml}$ extract was taken, and 3-4 drops of Molisch's reagent was added followed by $2 \mathrm{ml}$ of concentarted $\mathrm{H}_{2} \mathrm{SO}_{4}$ along the side of the tube. The mixture was allowed to stand for some time, and the appearance of red or violet color at the interphase of two layers indicates a positive result.

\section{Cardiac glycosides (Keller Kellani's test)}

To $2 \mathrm{ml}$ of extract, $5 \mathrm{ml}$ glacial acetic acid and a drop of ferric chloride were added. The mixture was then carefully underlayed with $1 \mathrm{ml}$ of concentrated $\mathrm{H}_{2} \mathrm{SO}_{4}$. Formation of brown ring at the interface indicated the presence of deoxy sugar being the characteristic of cardenolides.

\section{Phenols}

A small amount of extract was treated with aqueous $5 \% \mathrm{FeCl}_{3}$ and observed for deep blue or black color formation

\section{Amino acids}

About 2-5 drops of ninhydrin solution was added to $2 \mathrm{ml}$ of extract and was placed in water bath for 1-2 min. The presence of amino acids was indicated by the formation of purple color.

\section{Saponins (foam test)}

About $6 \mathrm{ml}$ of water was added to $2 \mathrm{ml}$ of extract in a test tube. Shaking of the mixture was done vigorously and observed for the formation of persistent foam which confirms the presence of saponins.

\section{Terpenoids (Salkowski's test)}

Nearly $1 \mathrm{ml}$ of chloroform was added to $2 \mathrm{ml}$ of extract which was followed by the addition of few drops of concentrated $\mathrm{HCl}$. The presence of terpenoids was confirmed by immediate formation of reddish brown precipitate.

\section{Test for Quinones}

A small amount of extract was treated with concentrated $\mathrm{HCl}$. Formation of yellow precipitate or coloration indicated the presence of quinones.

Estimation of phytochemicals with the help of spectrophotometer The plant extracts were subjected to quantitative estimation of phenolics and flavonoids. For the estimation of flavonoids and phenolic content present in the extracts, quercetin was taken as standard. 
Estimation for the presence of flavonoids

About $0.5 \mathrm{ml}$ of methanolic extract was mixed with $1.5 \mathrm{ml}$ of methanol followed by $0.1 \mathrm{ml}$ of $10 \%$ aluminum chloride, $0.1 \mathrm{ml}$ of $1 \mathrm{~m}$ potassium acetate, and $2.8 \mathrm{ml}$ of distilled water and then was kept at room temperature for around $30 \mathrm{~min}$. Measurement of the absorbance of mixture at $415 \mathrm{~nm}$ was performed with the help of spectrophotometer.

\section{Estimation for the presence of phenolic compound}

Folin-Ciocalteu (FC) method was used. $0.5 \mathrm{ml}$ of extract was mixed with $2.5 \mathrm{ml}$ of $1 / 10$ aqueous dilution of $\mathrm{FC}$ reagent. $2 \mathrm{ml}$ of $7.5 \%$ sodium bicarbonate was added after $5 \mathrm{~min}$, and the mixture was then incubated at room temperature for $2 \mathrm{~h}$. The absorbance of mixture was measured at $765 \mathrm{~nm}$ spectrophotometer.

\section{Antihemolytic analysis}

\section{Red blood cell (RBC) suspension}

Blood collected in heparinized tube was centrifuged at $3500 \mathrm{rpm}$ for 15 min. Plasma was removed with the buffy coat. In 10 volumes of $0.9 \% \mathrm{NaCl}, \mathrm{RBCs}$ were suspended and centrifuged at $2500 \mathrm{rpm}$ for 5 min. RBCs were washed thrice with the same solution. During the last washing, the packed cells were re-suspended in 10 volumes of PBS (pH 7.4) and was further used for the hemolysis assay [22].

\section{Assay for hemolysis}

In this, the effects were evaluated on ferrous ion-induced hemolysis. With $2.5 \mu \mathrm{m}$ ferrous sulfate, the RBC suspension was incubated.

After incubation, $4 \mathrm{ml}$ of PBS was added and centrifuged at $2500 \mathrm{rpm}$ for $5 \mathrm{~min}$. By measuring the optical density (OD) of the supernatant at $540 \mathrm{~nm}$, hemolysis was determined. For control sample, we can use reaction without extract. The percentage inhibition was calculated from the following equation:

\section{\%inhibition=([1-OD sample]/OD control $) * 100$}

\section{Statistical analysis}

Data obtained were analyzed for two-way ANOVA using GraphPad Prism 5.0. Level of significance was kept at 5\%.

\section{RESULTS}

\section{Antioxidant analysis}

\section{DPPH radical scavenging assay}

The free radical scavenging activity of methanolic extract of tested Ficus species was studied due to its ability to reduce the DPPH, a stable free radical. Any molecule that can donate hydrogen and electron to DPPH can react with it and thus bleach the DPPH absorption. The reduction ability of the DPPH radical by the decrease in its absorbance at $517 \mathrm{~nm}$ is induced by the antioxidants. The scavenging effects of extracts of three plants increased with their concentrations. The results of antioxidant activity for FB, FI, and FK were analyzed, of which FB showed maximum inhibition, i.e., $42 \%$, while FI showed minimum inhibition, i.e., $13 \%$ at $20 \mu \mathrm{g} / \mathrm{ml}$. At $40 \mu \mathrm{g} / \mathrm{ml}$, FB showed maximum inhibition, i.e., $51 \%$, while FK showed minimum inhibition, i.e., $43 \%$. At $60 \mu \mathrm{g} / \mathrm{ml}$, FB showed maximum inhibition, i.e., 58\%, while FK showed minimum inhibition, i.e., $48 \%$

At $80 \mu \mathrm{g} / \mathrm{ml}$ and $100 \mu \mathrm{g} / \mathrm{ml}$, FB showed maximum inhibition activity, minimum inhibition was shown by FI, while FK showed significant activity. $\mathrm{IC}_{50}$ values of $\mathrm{FB}, \mathrm{FI}$, and FK extracts were found to be 58.86 , 42.78 , and 47.87 , respectively, using DDPH scavenging assay, as per the results as shown in Fig. 1.

Two-way ANOVA was performed to assess the effect of concentration and type of extract on DPPH scavenging. It was observed that both the factors are having a significant effect on scavenging of DPPH radical $(\mathrm{p}<0.0001)$, i.e., there is a $<0.01 \%$ chance of randomly observing an effect this big in an experiment of this size.

\section{NO radical scavenging assay}

The production of NO radical at sustained levels results in direct tissue toxicity, while chronic expression of NO radical is related with various inflammatory conditions including juvenile diabetes, multiple sclerosis, arthritis, and ulcerative colitis [19]. Any compound natural or synthetic, with antioxidant properties, might contribute toward the partial or total alleviation of this damage. The results of antioxidant activity by NO scavenging assay for FB, FI, and FK were analyzed. As per the results obtained, methanolic extract of FI showed maximum inhibition activity, i.e., $45.53 \%$ in comparison to FB and FK. In contrast to this, acetonic extract of FB showed maximum inhibition activity, i.e., $43.57 \%$ when compared to FI and FK. However, in aqueous extract, FI showed maximum inhibition activity, i.e., $37.36 \%$, as compared to $\mathrm{FB}$, i.e., $30.16 \%$ and FK, i.e., $11.36 \%$. $\mathrm{IC}_{50}$ values of $\mathrm{FB}, \mathrm{FI}$, and FK plant extracts are 30.43 , 38.85 , and 18.65 , respectively, using NO radical scavenging assay, as per the results as shown in Fig. 2.

Two-way ANOVA revealed that the effect of extract type as well as the plant type on NO inhibition is not significant (plant type $\mathrm{p}=0.8411$ and extract type $\mathrm{p}=0.5503$ ). As the $\mathrm{p}$ values are greater than our significance level (5\%), we consider this effect to be nonsignificant.

\section{Antibacterial analysis}

The antibacterial activity was determined for aqueous, methanolic, and acetonic extract and the results are shown in Fig. 3a and b. Appearance of a clear zone of inhibition around the discs confirms the

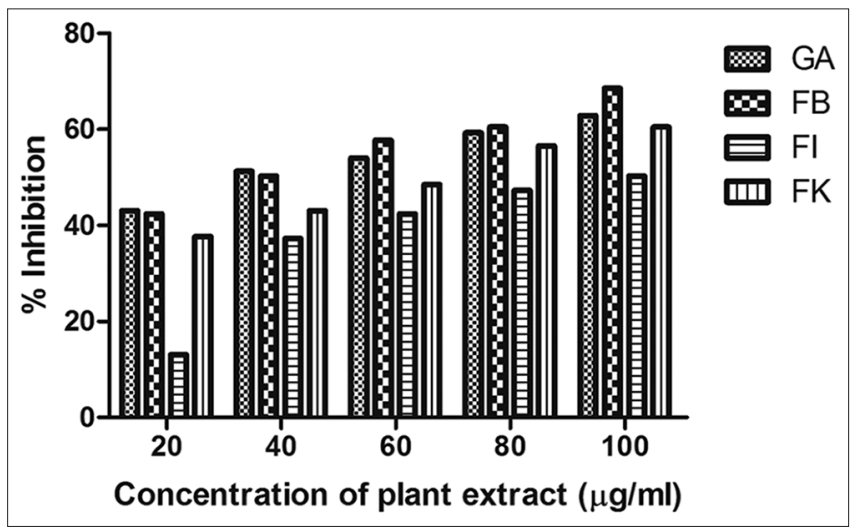

Fig. 1: Inhibition of 1-diphenyl-2-picrylhydrazyl radical by Ficus benjamina, Ficus infectoria, and Ficus krishnae at different concentrations with gallic acid as a control

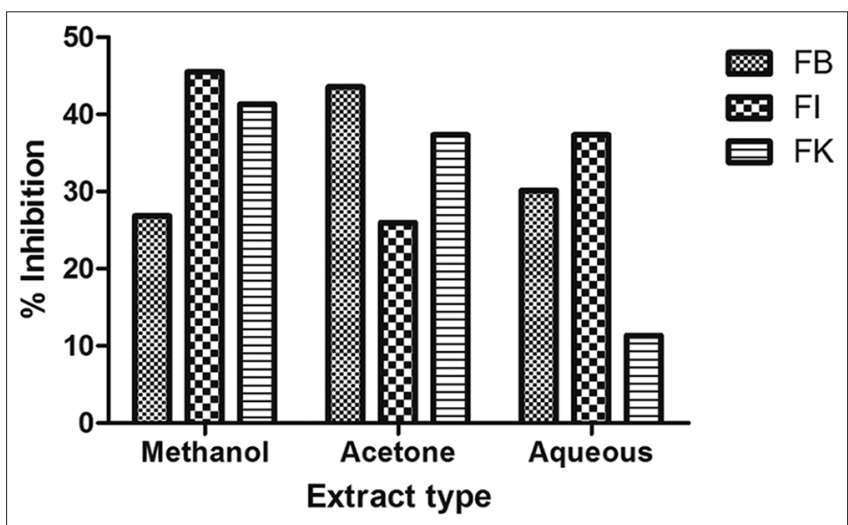

Fig. 2: Inhibition of nitric oxide by Ficus benjamina, Ficus infectoria, and Ficus krishnae 


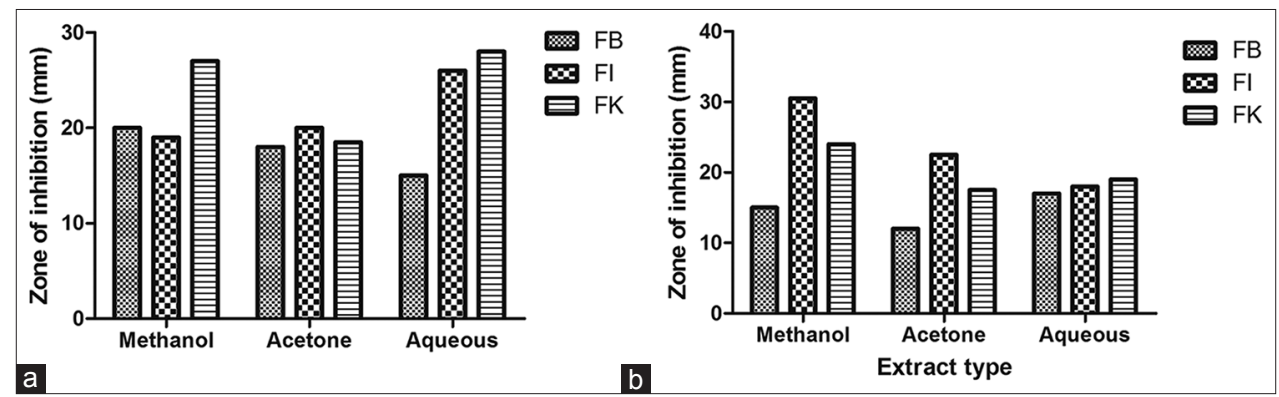

Fig. 3: (a) zone of inhibition (mm) as shown by Ficus benjamina (FB), Ficus infectoria (FI), and Ficus krishnae (FK) against Clostridium perfringens, (b) zone of inhibition (in $\mathrm{mm}$ ) as shown by by FB, FI, and FK against Staphylococcus aureus

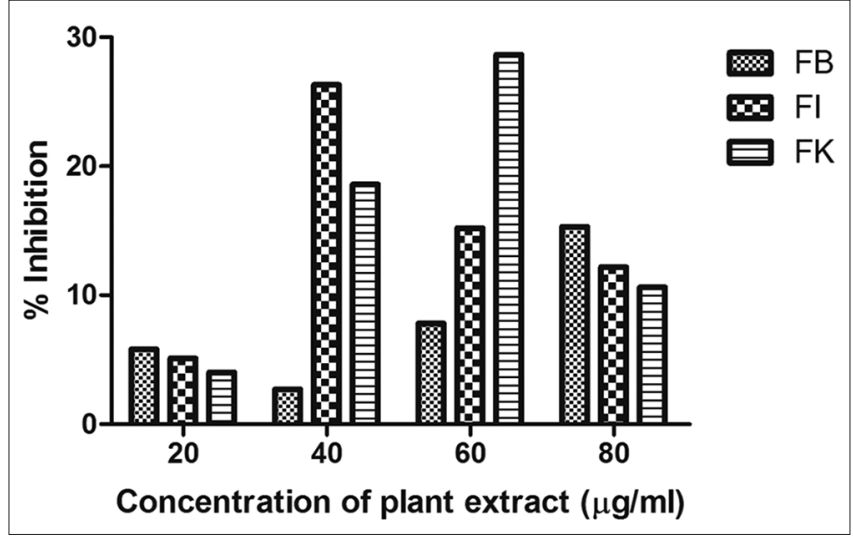

Fig. 4: Percentage inhibition activity shown by antihemolytic assay on the plant extracts

antibacterial activity of the chemicals present in the respective plant extract taken.

From Fig. 3a, it is revealed that aqueous extract of FK shows the maximum activity $(28 \mathrm{~mm})$ against $C$. perfringens. Aqueous extract of FB shows the minimal activity against $C$. perfringens $(15 \mathrm{~mm})$. On the other hand, Fig. $3 \mathrm{~b}$ depicts that the methanolic extract of FI shows the maximum activity $(30.5 \mathrm{~mm}$ ) against $S$. aureus. Acetonic extract of FB shows the minimal activity against the $S$. aureus.

\section{Antihemolytic activity}

The plant extract property was studied on RBC. By measuring the OD of supernatant at $540 \mathrm{~nm}$, hemolysis was determined.

At $40 \mu \mathrm{g} / \mathrm{ml}$, minimum inhibition was shown by $\mathrm{FB}$, i.e., $2.7 \%$ and FI showed maximum inhibition activity, i.e., $26.31 \%$. At $60 \mu \mathrm{g} / \mathrm{ml}$, FB showed minimum inhibition activity, i.e., $7.81 \%$ and FK showed maximum inhibition activity of $28.64 \%$, while FI shows significant activity, i.e., $15.21 \%$. At $80 \mu \mathrm{g} / \mathrm{ml}$, minimum inhibition was shown by FK, i.e., $10.6 \%$ and $\mathrm{FB}$ showed maximum inhibition activity of $15.31 \%$, while FI shows a significant activity, i.e., $12.19 \%$. Antihemolysis restricts hemoglobin to spread to the neighboring cells to protect them against diseases. FK has shown maximum percentage inhibition activity, i.e., $28.64 \%$ at $60 \mu \mathrm{g} / \mathrm{ml}$, whereas FB shows minimum inhibition activity, i.e., $2.7 \%$ at $40 \mu \mathrm{g} / \mathrm{ml}$ as depicted in Fig. 4.

Two-way ANOVA was performed to assess the effect of plant type and extract type on antihemolytic activity. P values for plant type factor is observed to be 0.3999 , while for extract type, is 0.3322 . In both the cases, the variation on the antihemolytic activity was considered as insignificant as the $\mathrm{p}$ values are much higher than our level of significance (5\%).

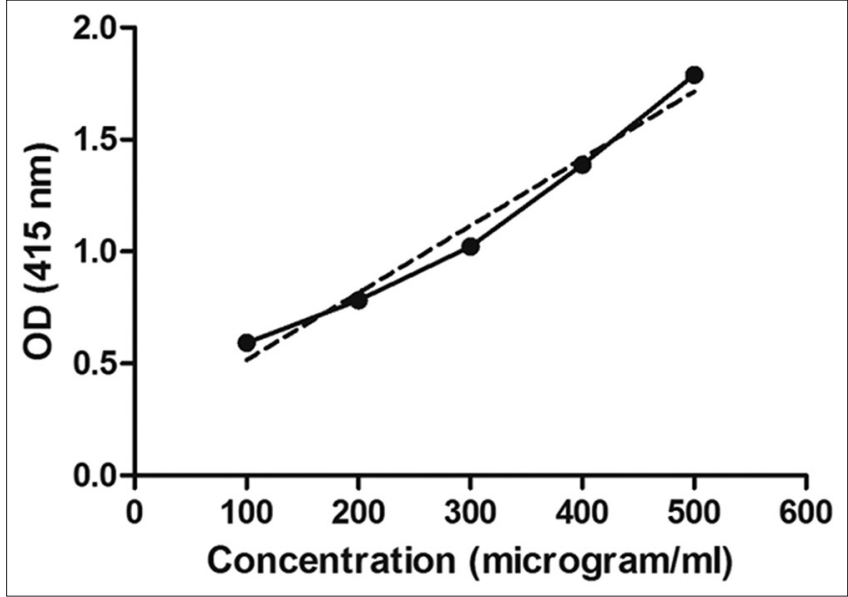

Fig. 5: Calibration curve at $415 \mathrm{~nm}$ for the flavonoid content estimation

\section{Phytochemical analysis}

Plant species were studied based on their phytochemical properties to discover medicinal benefits. A phytochemical is represented as a compound found in the plants that are biologically active compound with nutrients and dietary fiber to protect against disease. FI showed the maximum presence of phytochemicals when compared with FB and FK. From the results obtained, it can be concluded that aqueous extract of three plants showed positive results for saponins and phenols. Methanolic extract of FB, FI, and FK gave a negative test for flavonoids and saponins. For carbohydrates, phenols, quinones, and cardiac glycosides, FB and FK showed negative result, while positive result was shown by FI as shown in Table 1.

Acetonic extract of FB and FI shows a significant presence of phytochemicals when compared to FK.

\section{Flavonoid content estimation}

For the estimation of flavonoids, methanol was taken as standard. The absorbance at different concentrations of methanol was taken at $415 \mathrm{~nm}$ for preparing standard curve (Fig. 5) with concentration versus absorbance value.

\section{Phenolic content estimation}

For the estimation of phenols, querectin was taken as standard. The absorbance at different concentrations was taken at $765 \mathrm{~nm}$ for preparing the standard curve (Fig. 6).

\section{DISCUSSION}

Medicinal herbs and plants are very well recognized for their wide variety of phytochemicals and phenolic compounds such as 
Table 1: Phytochemical analysis

\begin{tabular}{|c|c|c|c|c|c|c|c|c|c|}
\hline \multirow{2}{*}{$\begin{array}{l}\text { Plant } \\
\text { Test }\end{array}$} & \multicolumn{3}{|c|}{ Ficus benjamina } & \multicolumn{3}{|c|}{ Ficus infectoria } & \multicolumn{3}{|c|}{ Ficus krishnae } \\
\hline & Acetone & Aqueous & Methanol & Acetone & Aqueous & Methanol & Acetone & Aqueous & Methanol \\
\hline Amino acid & + & - & - & - & - & - & - & - & + \\
\hline Saponins & - & + & - & - & + & - & - & + & - \\
\hline Carbohydrate & + & - & - & + & + & + & - & - & - \\
\hline Phenols & + & + & - & - & + & + & - & + & - \\
\hline Quinines & - & - & - & + & + & + & - & + & - \\
\hline Terpenoids & + & - & + & - & + & - & - & + & - \\
\hline Alkaloids & + & - & + & + & - & + & - & + & - \\
\hline Cardiac glycosides & - & - & - & + & + & + & + & + & - \\
\hline
\end{tabular}

+=For the presence, -: For the absence

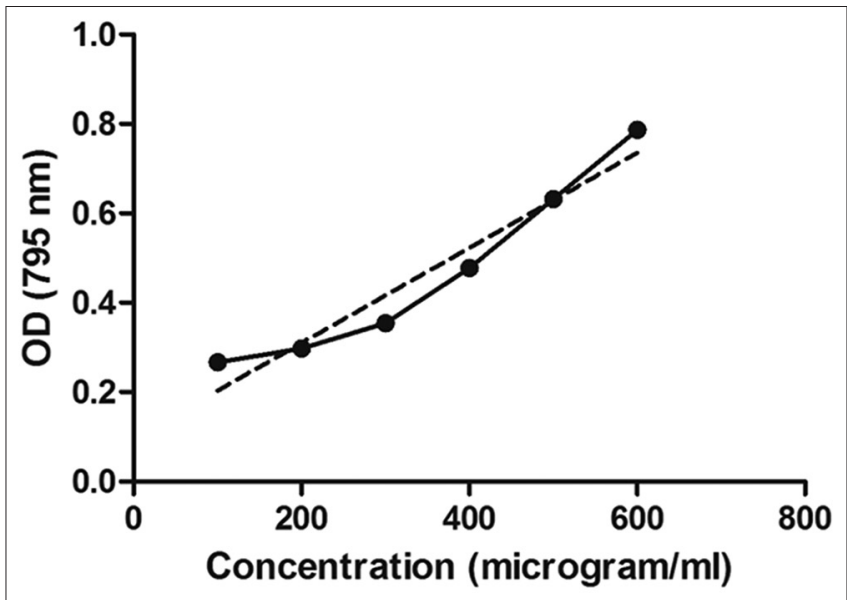

Fig. 6: Calibration curve at $765 \mathrm{~nm}$ for the phenolic content estimation

flavonoids which act as an antioxidant for scavenging free radicals and inhibit lipid peroxidation. Extracts of FB, FI, and FK were screened for their antibacterial activity against bacterial strains of $C$. perfringens and $S$. aureus. Of three plant species tested, FB showed a maximum zone of inhibition against $C$. perfringens $(20 \mathrm{~mm})$, FI showed a maximum zone of inhibition against $S$. aureus (30.5 mm), and FK showed a maximum zone of inhibition against $C$. perfringens $(28 \mathrm{~mm})$. The aqueous extract of $F$ religiosa has shown high antimicrobial activity against $S$. aureus and B. subtilis [23]. For different extracts of Ficus, diethyl ether extract was used and exhibited better inhibitory effect against $K$. pneumonia $(20 \mathrm{~mm})$, E. coli $(12 \mathrm{~mm})$, and P. aeruginosa $(12 \mathrm{~mm})$ and minimum activity was shown against $S$. aureus $(10 \mathrm{~mm})$ [24]. The presence of various phytochemicals such as saponins and alkaloids was reported in the leaf extracts of Ficus species [25].

The phytochemical analysis of aqueous, acetonic, and methanolic extract was easily performed for qualitative analysis of flavonoid, phenols, saponins, cardiac glycosides, terpenoids, quinones, carbohydrates, and alkaloids. A widespread variety of vigorous phytochemicals such as flavonoids, alkaloids, and saponins have been isolated and identified in different plants of Ficus family. As the results obtained, it can be concluded that aqueous extract of three plants shows positive results in case of saponins and phenols, it gave a negative result in case of amino acid, as it is absent in aqueous extract of FB, FI, and FK. In case of methanolic extract, all three gives a negative test for flavonoids and saponins. For carbohydrates, phenols, quinones, and cardiac glycosides FB and FK have a negative result while positive result is shown by FI.

FI showed higher phytochemical activity than other two. The flavonoid content was found to be $693 \mu \mathrm{g} / \mathrm{ml}, 1007 \mu \mathrm{g} / \mathrm{ml}$, and $1150 \mu \mathrm{g} / \mathrm{ml}$ in FB, FI, and FK, respectively. The phenolic content was found to be $258 \mu \mathrm{g} / \mathrm{ml}, 260 \mu \mathrm{g} / \mathrm{ml}$, and $340 \mu \mathrm{g} / \mathrm{ml}$ in FB, FI, and FK, respectively.

The antioxidant analysis of FB, FI, and FK was performed for measuring percentage inhibition of plant extracts at different concentrations. $\mathrm{IC}_{50}$ values of $\mathrm{FB}, \mathrm{FI}$, and FK plant extracts are $58.86,42.78$, and 47.87 , respectively, using DDPH scavenging assay. Antioxidant activities are due to the presence of various phytochemicals such as flavones, isoflavones, flavonoids, anthocyanin, catechins, and isocatechins. Herbal extracts of FK showed anticancer activity against human cell lines bread MCF7, renal TK10, and UCC62. This was based on antioxidants present in FK which is responsible for anticancer activity [26].

The antihemolytic activity of FB, FI, and FK was performed by measuring percentage inhibition of plant extracts at different concentrations. Antihemolysis restricts hemoglobin to spread to the neighboring cells to protect them against diseases. FK has shown maximum percentage inhibition activity, i.e., $28.64 \%$ at $60 \mu \mathrm{g} / \mathrm{ml}$, whereas FB shows minimum inhibition activity, i.e., $2.7 \%$ at $40 \mu \mathrm{g} / \mathrm{ml}$.

\section{CONCLUSION}

Plants are natural sources providing the richest source of organic chemical on earth. The increasing failure of chemotherapeutics and antibiotic resistance exhibited by pathogenic microbial infectious agents led to the screening of several medicinal plants such as FB, FI, and FK. We have concluded that FB, FI, and FK extracts contain various phytochemicals which confirm that these plants can be used for therapeutic use and traditional medicine. From the work, it can be concluded that the methanolic as well as aqueous extracts of FB, FI, and FK have the potential to kill the tested microorganism (C. perfringens and $S$. aureus). Hence, they can be used as the antibiotic and potential antibacterial.

Research is being required to identify the chemical nature of active substances with their modes of action on various bacterial cells and their roles to cure disease. Phytochemical testing was done for the plant species, and a significant number of phytochemicals were found to be present in all the three extracts, i.e., acetonic, aqueous, and methanolic extracts. The phytochemical broadcast of the extracts of the plants tested exposed the presence of flavonoids, saponins, phenolic, terpenoids, cardiac glycosides, etc. Thus, it can be suggested that the three plants which were examined have the potential to be used as drugs or agents against various infectious diseases as it already shows antibacterial activity. However, further studies are still required concerning the efficiency in the presence of infection and safety report when applied on infected skin or mucous membrane. Hence, for this, clinical trials are required. An attempted study is used to increase the antibacterial activity of FB, FI, and FK extracts. To overcome several problems generated by various microorganisms, antimicrobial compound of FB, FI, and FK provides great opportunity in the field of natural product chemistry, pharmacognosy, pharmacology, and other fields of life sciences. Furthermore, substances derived from plants act as a basis for commercial production which is used in developing countries [26]. 


\section{AUTHORS' CONTRIBUTIONS}

Concept, design, intellectual content, and supervision - Mr. Prabhjot Singh Jassal. Literature review - Ms. Monika Sharma. Data collection, analysis, and interpretation - Mr. Prabhjot Singh Jassal and Ms. Monika Sharma. Drafting of article and revising it critically for important intellectual content and review - Mr. Prabhjot Singh Jassal and Ms. Monika Sharma.

\section{CONFLICTS OF INTEREST}

The authors declare that they have no conflicts of interest

\section{REFERENCES}

1. Ghani, A. Medicinal Plants of Bangladesh: Chemical Constituents and Uses. Dhaka: Asiatic Society of Bangladesh; 1998.

2. Dhar ML, Dhar MM, Dhawan BN, Mehrotra BN, Ray C. Screening of Indian plants for biological activity: I. Indian J Exp Biol 1968;6:232-47.

3. Mousa O, Vuorela P, Kiviranta J, Törnquist K, Vuorela H, Hiltunen R. Bioactivity of certain Egyptian Ficus species. Plant Med 1992;58:632-3.

4. Elgimabi ME. Improvement of propagation by hardwood cuttings with or without using plastic tunnel in Hamelia patens. World J Agric Sci 2009;5:522-4.

5. Rzepka-Plevnes D, Kurek J. The Influence of Media Composition on the Proliferation and Morphology of Ficus benjamina plantlets. In: IV International Symposium on In Vitro Culture and Horticultural Breeding, ISHS Acta Horticulturae 560. 2000. p. 473-6.

6. Almahy HA, Rahmani M, Sukari MA, Ali AM. The chemical constituents of Ficus benjamina Linn. And their biological activities. Pertanika J Sci Technol 2003;11:73-81.

7. Sasi S, Anjum N, Tripathi YC. Ethnomedicinal, phytochemical and pharmacological aspects of Flacourtia jangomas: A review. Int J Pharm Pharm Sci 2018;10:9-15.

8. Singh D, Singh B, Goel RK. Traditional uses, phytochemistry and pharmacology of Ficus religiosa: A review. J Ethnopharmacol 2011;134:565-83

9. da Rocha AB, Lopes RM, Schwartsmann G. Natural products in anticancer therapy. Curr Opin Pharmacol 2001;1:364-9.

10. Husain A, Virmani OP. Dictionary of Indian Medicinal Plants. Lucknow, India: Central Institute of Medicinal and Aromatic Plants; 1992.

11. Ambike SH, Rao MR. Studies on phytosterolin from the bark of Ficus religiosa. Znd J Pharm 1967;29:91
12. Swami KD, Bisht NP. Constituents of Ficus religiosa and Ficus infectoria and their biological activity. J Indian Chem Soc 1996;73:631.

13. Kumari M, Sharma A, Jagannadham MV. Decolorization of crude latex by activated charcoal, purification and physico-chemical characterization of religiosin, a milk-clotting serine protease from the latex of Ficus religiosa. J Agric Food Chem 2010;58:8027-34.

14. Biswas K. Observations on the systematic position of Ficus krishnae. Curr Sci 1934;3:424-7.

15. Shukla R, Gupta S, Gambhir JK, Prabhu KM, Murthy PS. Antioxidant effect of aqueous extract of the bark of Ficus bengalensis in hypercholesterolaemic rabbits. J Ethnopharmacol 2004;92:47-51.

16. Charde RM, Dhongade HJ, Charde MS, Kasture AV. Evaluation of antioxidant, wound healing and anti-inflammatory activity of ethanolic extract of leaves of Ficus religiosa. Int J Pharm Sci Res 2010;19:73-82.

17. Sandhu A, Bhardwaj N, Gupta R, Menon V. Antimicrobial activity and photochemical screening of Tinospora cordifolia and Euphorbia hirta. Int J Appl Biol Pharm Technol 2013;4:310-6.

18. Varier PS. Indian Medicinal Plants: A Compendium of 500 Species. Vol. 1. Kottakkal-India: Orient Longman Publishing House; 2002. p. 146.

19. Braca A, Tommasi ND, Bari LD, Pizza C, Politi M, Morelli I. Antioxidant principles from bauhinia $t$ arapotensis. J Nat Prod 2001;64:892-5.

20. Taylor BS, Kim YM, Wang Q, Shapiro RA, Billiar TR, Geller DA, et al. Nitric oxide down-regulates hepatocyte-inducible nitric oxide synthase gene expression. Arch Surg 1997;132:1177-83

21. Ugochukwu SC, Uche A, Ifeanyi O. Preliminary phytochemical screening of different solvent extracts of stem bark and roots of Dennetia tripetala G. Baker. Asian J Plant Sci Res 2013;3:10-3.

22. Thephinlap C, Pangjit K, Suttajit M, Srichairatanakool S. Anti-oxidant properties and anti-hemolytic activity of Psidium guajava, Pandanous odorus and Rhinacanthus nasutus. J Med Plants Res 2013;7:1849-57.

23. Shamila IM, Jeeva S, Sheela DJ, Brindha JR, Lekshmi NC. Antimicrobial spectrum and phytochemical study of Ficus tsiela L. (Moreceae) Drug Invent Today 2012;4:337-9.

24. Tijjani AM, Abdurahaman IF, Buba WS, Mala IG, Akan CJ, Babakura MA. Chemical and proximate contents of methanolic leaf extract of Piliostigma thonningii Schum (Camel foot). J Chem Pharm Res 2012;4:2409-14

25. Fouche G, Cragg GM, Pillay P, Kolesnikova N, Maharaj VJ, Senabe J, et al. In vitro anticancer screening of South African plants. J Ethnopharmacol 2008;119:455-61.

26. Saiah H, Allem R, Kebir FZ. Antioxidant and antibacterial activities of six Algerian medicinal plants. Int J Pharm Pharm Sci 2016;8:367-74. 